\title{
E. Donnall Thomas (1920-2012)
}

\author{
Robert Peter Gale
}

Published online: 2 December 2012

(c) The Japanese Society of Hematology 2012

Professor E. Donnall Thomas of the Fred Hutchinson Cancer Research Center, 1990 Nobel laureate in Physiology or Medicine and a pioneer in bone marrow transplantation died in Seattle on 20 October 2012. He was 92 years old and remained active and engaged in science and research until his death.

Don, as he was widely called, studied chemistry at the University of Texas, Austin and medicine at Harvard. His post-doctoral training was at Harvard and MIT. In 1955, he transferred to a Columbia University hospital where he and Joseph Ferrebee did the first successful bone marrow transplant between twins, one of whom had leukaemia in 1956. In 1963, Don moved to the University of Washington in Seattle and thence to the Fred Hutchinson Cancer Research Center in 1974.

Sometimes good may come as a consequence of something terrible such as the atomic bomb explosions. Don Thomas's interest in bone marrow transplantation was sparked by research that followed development of the atomic bombs. Beginning in the 1940s, the US Government recruited scientists to the National Institutes of Health in Bethesda and the University of Chicago to participate in biological and medical research aspects of the Manhattan project. Their remit was determining ways to counter effects of radiation on humans, especially bone marrow failure. In 1950, Jacobsen and colleagues reported shielding of the spleen and later intra-peritoneal injection of spleen cells could "protect" an irradiated mouse from death. In 1952, Lorenz, Congden and Uphoff show infusing bone marrow cells could also rescue lethally irradiated

R. P. Gale $(\bowtie)$

Section of Haematology, Division of Experimental Medicine, Department of Medicine, Imperial College, London, UK e-mail:rgale@celgene.com

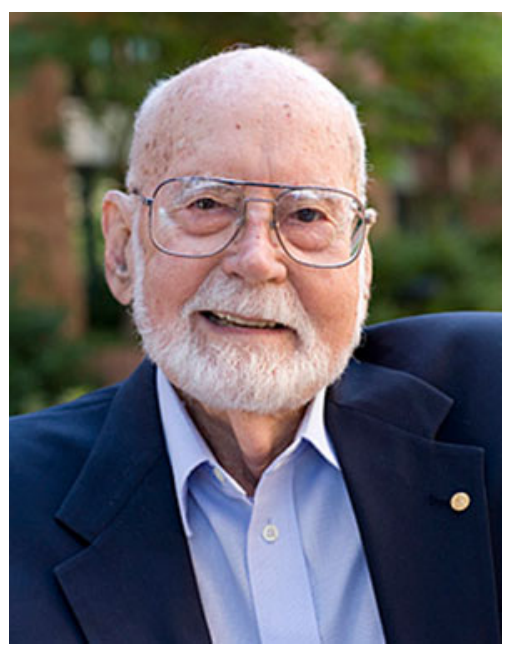

mice and guinea pigs. Then in 1952, Main and Prehn showed that a chimera mouse would accept a skin graft from the bone marrow donor, and Ford used cytogenetics to prove hematopoietic recovery was from donor bone marrow cells. In 1962, Barnes, Loutit and Micklem described secondary disease (primary disease was graftrejection) which Simonsen in 1965 correctly identified as graft-versus-host-disease (GvHD). And in 1966, Billingham and Medawar laid out immunological requirements for graft-rejection and GvHD. The gauntlet was thrown and Don Thomas seized on these data and spent the rest of his life perfecting bone marrow transplants, first in dogs and later in persons with advanced leukaemia brought us to where we are today: 65,000-70,000 transplants are done each year worldwide. Thousands of lives are saved.

Many others contributed to development of bone marrow transplantation including Robert A. Good, George Santos, Fritz Bach, Richard Gatti, Mortimer Bortin, Dirk van Bekkum, Jon von Rood, Georges Mathe' and others 
whom I shall never be forgiven for not mentioning. All made important contributions but none stayed the course like Don Thomas. Quoting his wife (and secret weapon) Dottie Thomas: "Don was indeed always patient, thorough and tenacious (some say stubborn). He did not give up easily and he truly enjoyed working at the bedside as well as in the theoretical aspects of transplantation."

Don believed strongly in sharing fruits of his research and in international collaboration. He was a founding member of the International Bone Marrow Transplant Registry and had many Japanese colleagues and collaborators, especially Professors Ken-ichi Hattori and Fumimaro Takaku. Many Japanese transplant specialists trained with Don and his colleagues at Seattle and are now leaders in Japanese haematology. But I am especially grateful to Don Thomas for not having immediate space in his program for Professor Mine Harada who subsequently came to study at UCLA and became a life-time collaborator and friend. Another example of unintended consequences.

Don Thomas had a special fondness for Japan and for his Japanese colleagues and students. I know he will be greatly missed.

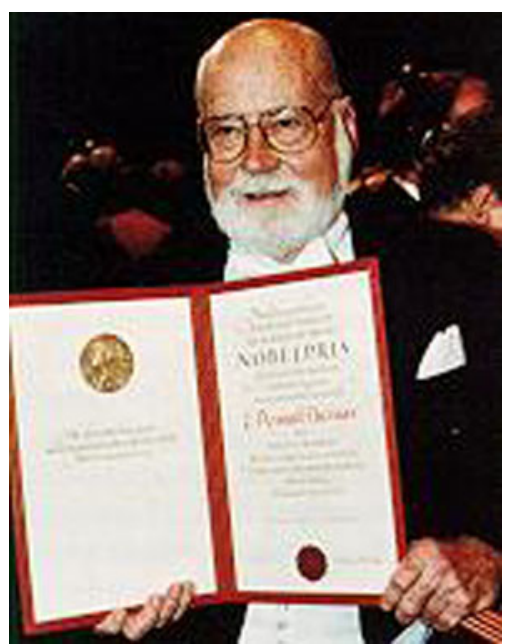

Robert Peter Gale MD, PhD, DSc (hon) FACP Section of Haematology, Division of Experimental Medicine, Department of Medicine, Imperial College, London, UK 